\title{
Re-use of historical buildings in the holy city of Makkah: case study selection guidelines
}

\author{
M. I. Elbelkasy ${ }^{1}$, J. M. AlSalafi ${ }^{1} \&$ M. F. Mahmoud ${ }^{2}$ \\ ${ }^{1}$ Department of Islamic Architecture, \\ Umm Al-Qura University, Saudi Arabia \\ ${ }^{2}$ Department of Architecture, Effat University, Saudi Arabia
}

\begin{abstract}
When dealing with heritage conservation, the holy city of Makkah comes as one of the most sensitive cases to deal with. This is mainly due to the pace of development in the central area surrounding Almasjed Alharam (The Holy Mosque). This paper explores the standards of rehabilitation and re-using of historic buildings in that special region. The importance of the study arises from the urgent need to address issues of heritage and conservation amid fast developments and transformations of the urban fabric of the holy city of Makkah. The methodology is based on both theoretical and applied analytical approaches. Theoretically, the research contextualizes for the development of the holy city of Makkah, by introducing its heritage, socio-economic, cultural and political factors that have been on the scene for long. Finally, the study concludes by presenting a case study for dealing with heritage buildings within the context of development that is taking place in the area.
\end{abstract}

Keywords: conservation, rehabilitation, re-use, heritage buildings.

\section{Introduction}

Rehabilitation and re-use of heritage buildings is a great potential and vehicle for developing heritage districts. However, this comes with certain qualifications, especially when talking about some unique districts and/or regions. In our case, the holy city of Makkah comes as one of the most unique cases with its place in the hearts of Muslims and its relation to worship and religious rituals.

Therefore, when dealing with it there should be a comprehensive study of the investment benefits and its ability to serve visitors of the Holy Mosque, without 
prejudice to the sanctity of the place and can therefore be influenced by architectural heritage in the central area surrounding the Holy Mosque.

This research paper poses an important question; "How would investments in this district serve the heritage of Makkah without demeaning its religious and holy value for Muslims around the world?"

The basic assumption of this study is that Makkah has its own set of variables that forms a special context for development. These should be observed, assessed and dealt with sensitively. The paper concludes by setting some standards for selecting heritage buildings for re-use and rehabilitation in different zones of the holy city of Makkah, in a way that conserves the architectural heritage of the city and ensures economic development sought by investors.

To reach these goals, the paper delineates conservation processes for the urban and architectural heritage of Makkah, sets up a map for the important heritage buildings and other neglected ones and finally suggests tools for dealing with heritage buildings that might be demolished of expansions of the holy mosque.

\section{The holy city of Makkah: constants and variables in urbanization of holy Makkah}

The holy city of Makkah originated around the Holy Mosque after the Prophet Abraham and his son Ismail built Kaaba and urbanism began in this area that the God honored by the existence of the Holy Mosque, the urbanism evolution of Makkah since that and the development over the years was based on the Holy Mosque.

Studying the history of the emergence and growth of holy Makkah, we find that there is always a group of constants represented in the Kaaba and different areas where Muslims perform the Islamic rituals and there are many variables based on the service of prior constants.

\subsection{Urban fabric of holy Makkah}

The urban fabric in holy Makkah has many characteristics that gave it a kind of exclusivity than any other city in the world, and to study the nature of the urban fabric of Makkah we must first study the factors that influenced the formation of the city through ages, which are the geographical location, topography of the city and architectural details that formed the urban fabric of holy Makkah.

The geographical location and topography are the most important factors that have affected the traditional architecture in Makkah [1], which produced a distinctive architecture and the effect of geographical and topography location of the land can be summarized as follows:

Holy Makkah is located in the west of Saudi Arabia and about 70 kilometres from the Red Sea to the east at longitude 40 degrees east line GMT latitude 21.5 degrees north of the equator and rising from the sea by 280 meters. It is located in a valley surrounded by mountains on all sides and as a result of its location in the tropical region, which affects the form and nature of the traditional architecture. Fig. 1. 

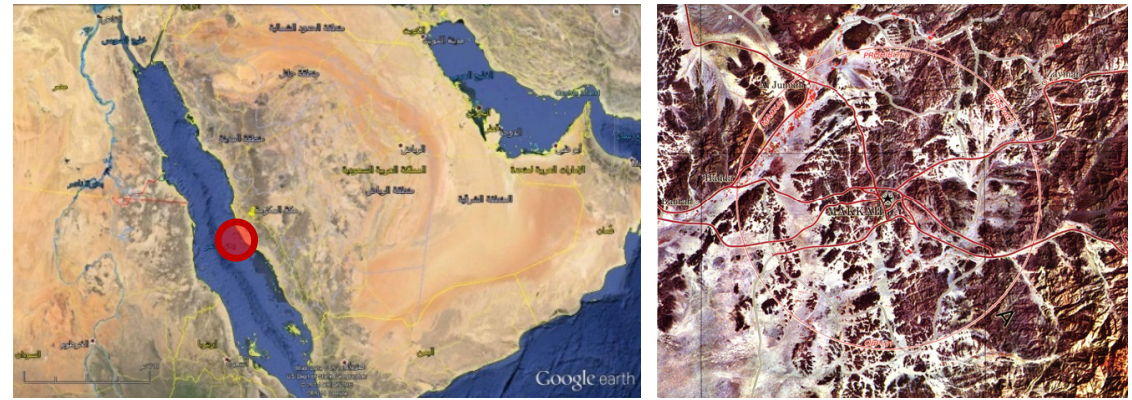

Figure 1: Geographic location and topography of holy Makkah.

The topography of holy Makkah influenced the formation of urbanization and architecture of the city, it is located on the slopes of the Sarwat mountains, and represents a meeting point between Tehama and mountains. Due to the rapid urban development, the mountains "which were recognized as a natural boundary of the city" transformed to be one of the main components of the central area. The most important and famous mountains are Mount Qaikaan and Mount Abu Qubeis and Indian Mountain and Mount Khandma [2]. This normal configuration has contributed in forming an urban environment with a unique character and distinct. It takes into account the environmental conditions (natural and climatic) and social and economic development, Fig. 1.

\subsection{Holy Makkah traditional architectural character}

Makkah architecture is an integral part of the western region architecture in the Kingdom (Hijaz Architecture), which shows where many of the characteristics that are compatible with the nature of the climate, the environment and terrain characteristics of Makkah architecture that may be described by that name, and can be summarized in these properties in the following:

a. The vertical height (multiple floors) as the height of the building to six floors.

b. The disappearance of the inner courtyard and the upper gradient in the blanks (outflow) due to the limited land area and difficult terrain.

c. Building using stones that are extracted from the mountains surrounding Makkah and processed to become suitable for construction work.

d. Using prominent wooden decorations that cover most of the facades of the building to achieve privacy and environmental friendliness, Fig. 2.

\subsection{Factors affecting the heritage conservation and re-use in the central area of holy Makkah}

There are two main factors that affect architecture and heritage of the central area and can be summarized as follows: 


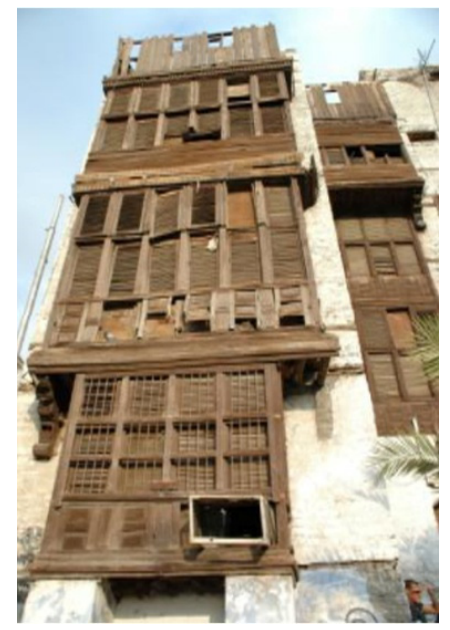

Figure 2: Models of traditional architecture in holy Makkah.

\subsubsection{Expansions of the Holy Mosque}

It is one of the most important factors that affects architecture of the central area over the centuries. As a result of this factor, we find that there are many of the characteristics of urbanization in the area which have changed as a result of expansion of the Holy Mosque, which is the most important constants in the architecture of Makkah, and any heritage importance of the surrounding buildings become less important. The Holy Mosque and its rituals are the most essential foundation for the planning of the central area, and on the basis of standards and determined the nature of buildings and facilities and arenas around it, with respect for the privacy of Makkah and its religious status as a safe sanctuary and its relationship with sacred sites, Fig. 3.

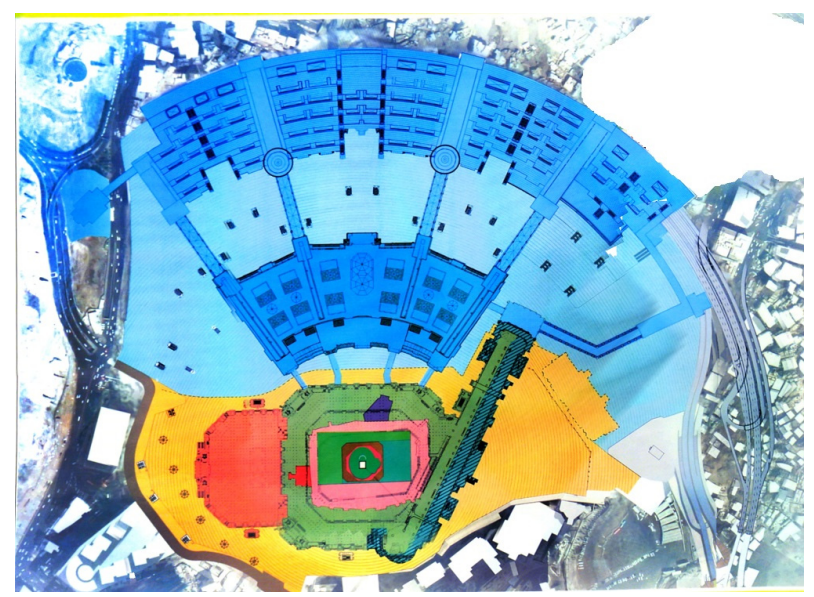

Figure 3: Expansion of Holy Mosque through different ages. 


\subsubsection{Investment projects in the central area of holy Makkah}

The investment projects in the central area are one of the most important factors influencing the architectural heritage in the central area. That is because of the importance of the area as it is near the Holy Mosque and the great high value of land in the area, Fig. 4. Although there are new projects, many of the services needed near the central area, as it represents one of the most important investment opportunities in the area [3], but they have had negative effects that can be summarized as follows:

a. Visual image has changed in the area, and this affects the importance of the Holy Mosque with its high minarets as the visual parameter forces to the area (King Abdul Aziz building became the visual point of attraction for the area).

b. New buildings did not maintain the architectural properties of the heritage and there was no consensus or homogeneity among a group of buildings, both in the size of projects or heights or physical character.
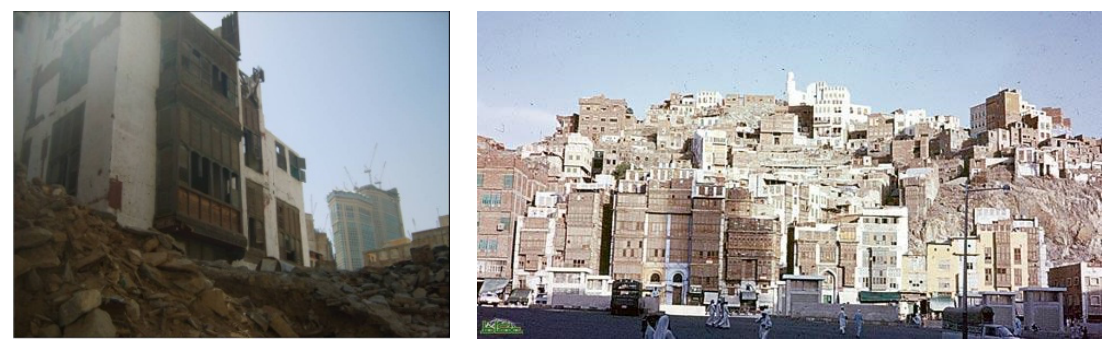

Figure 4: Heritage affected by Holy Mosque expansion and investment projects.

\section{Conservation and re-use heritage building strategy in holy Makkah}

Holy Makkah is distinguished, (especially the central area) with its high ability to attract urban investment due to the high return-back of investment projects and relative scarcity of the area which reduces the investment risk, which drew the attention of many developers to invest in many service projects. To ensure sustainability of the development process, social and local development should be integrated with economic development. Local development processes for the built environment takes into account the topography, climate, and architectural character and heritage, which maintains not only the values of static buildings (shape and architectural character), but the place features and specialty that achieved by the following.

\subsection{Strategy first step: to maintain the dominance of the Holy Mosque image on the visual perception of the area}

The Holy Mosque is the main controller of investment operations in the area and that all working to take advantage of the proximity of it and provide the necessary 
services for pilgrims, but in order to build new buildings we should put into consideration the investment equation and maintain the visual image of the area, and we should stick to the following criteria:

a. Scale: You must take into account the scale of new buildings measure of the Holy Mosque to keep the visual image of the area.

b. Architectural character: the architectural character must comply with the architectural heritage character of the area and this does not mean the transfer of heritage as it is, but the compatibility of new buildings with heritage of the area and the architectural character of the Holy Mosque.

c. Building materials: materials must be compatible with the nature of the construction area where a stretch of the Holy Mosque and one of the most important factors in the use of building materials are subject to change or remove a building at the lowest costs.

d. Documentation of the nature of the architectural heritage of the area: a result of changing the physical character of the central area where the utmost importance is to expand the campus and services for pilgrims, it must be before the demolition of buildings that has heritage which features Hijazi architecture to be a comprehensive documentation of these buildings and the architecture and shape of the urban fabric and activities, customs and traditions inherited and the impact in the form of an urban fabric [4].

\subsection{Strategy second step: historical and heritage buildings outside the central area}

They must be maintained and reused because of their physical and moral important values of the society in Makkah.

\section{Heritage conservation policy in holy Makkah}

From previous study, the research suggests working on three levels to conserve the heritage of holy Makkah, Fig. 5. These levels are summarized as a set of domains in which they are applying a set of different policies to maintain these areas as follows:

\subsection{Red zone (A)}

The only constant which is in and around the Kaaba to provide services to the campus and only pilgrims, in this area heritage should be documented to take advantage of it in the case of demolition or loss (Al-Shamia area).

\subsection{Gray area (B)}

The inventory of heritage buildings, conserve and repurpose according to the importance of each building including maintaining the distinctive urban character of the buildings on the mountains with the development of these areas and providing services and facilities. 


\subsection{White area (C)}

A reformulation of urban and architectural heritage, which has been documented in the central area to take advantage in these areas in the image constructivism legislation.

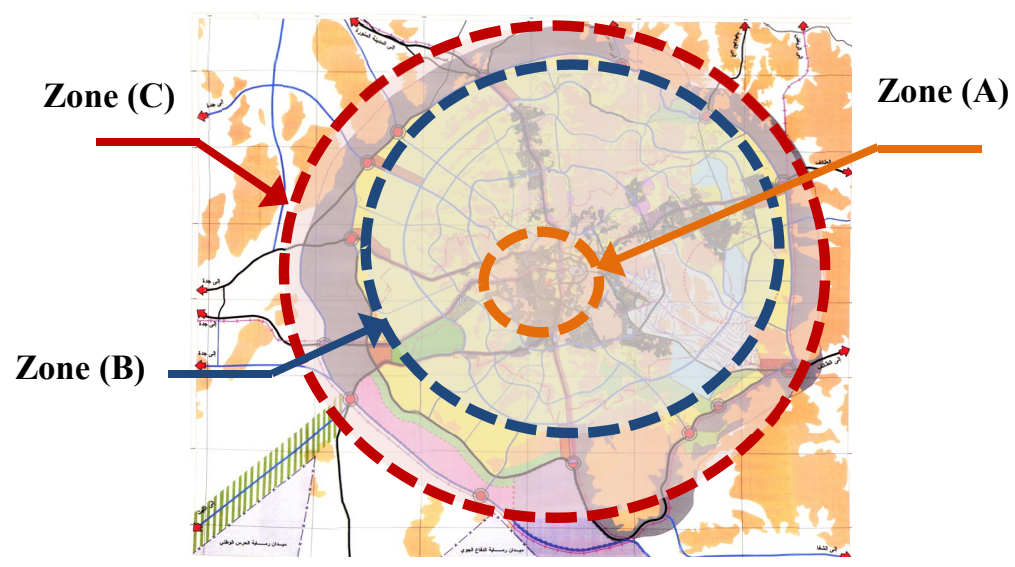

Figure 5: The three conservation proposed areas of holy Makkah.

\section{Why to conserve heritage building}

Reasons of heritage building conservation can be summarized in the following points [5]:

a. Social and historical reasons: Buildings reflect political and cultural properties of the age which it built in.

b. Building and historical events: Building can attend historical events which increase its value like Egyptian revolution council which attended 23 of July revolution and Al-Saqaf Palace which attended Al Hijaz people's allegiance to King Abdulaziz.

c. Economic reasons: Heritage is one of the most important incomes especially when we use it in tourist and cultural purposes.

d. Political reasons: Heritage buildings can reflect the political situation and the authority strength, values and stability.

e. Local reasons: Building gets its importance because it was an important person home like politicians, artists and poets.

f. Building importance: Building importance can be related to its architectural and structure system.

\section{Heritage buildings adaptive re-use}

Adaptive reuse is the act of finding a new use for a building. It is often described as a "process by which structurally sound older buildings are developed for 
economically viable new uses" [6]. The recycling of buildings has been an important and effective historic preservation tool for a long time. The re-use main goal is using building in the same purpose which made for because it's suitable for building structure and spaces, but when we can't use the heritage building in the same purpose, we can re-use it in another culturally, scientifically or touristic purpose after answering the following questions [7]:

- The present use of the building: can it still be used for this with or without modification to the structure?

- What is the structural condition of the building? Is it sound?

- What other uses might be suitable for the building?

- What funds are available, and how do these fit in with the possibilities explored in the rest of the study?

\subsection{Reasons of heritage building adaptive re-use}

The adaptive re-use process is one of the most important processes of heritage conservation which help buildings to stay for long time. The main reason of reuse buildings is related to that the building doesn't perform its original use because political, planning, technological and urban development reasons [8].

\section{Guide lines for case study selection}

Makkah is very sensitive case because of two main reasons. The first is privacy of Almasjed Alharam which is the most important constants in the architecture of Makkah. The second one is rapid development especially in the central area. So guide lines must respect these reasons. From the previous items, the guide lines can be summarized as the following:

\subsection{The distance from Almasjed Alharam}

Distance from Almasjed Alharam is one of the most important guide lines of choosing building to be re used because in central area according to conservation policy in holy Makkah the holy mosque is the only constant so this area can be documentation area only, but if there isn't a conflict between heritage re-use and the previous principal, it will be better to re-use these buildings in uses serve the holy mosque.

\subsection{Building importance}

The importance of the building is related to many factors like building architecture, structure and building architectural character. Makkah has a lot of heritage building have distinguished architectural character in several areas in the holy city especially in central area.

\subsection{Political considerations}

Political considerations appears when the building attends historical or political event which gives it additional importance. Makkah was the capital of Alhijaz 
region and the city was the center of a lot of political and historical events especially in the third Saudi kingdom.

\subsection{Building new use}

Building new use is one of the most important factors when we choose the building because the new use of the building must be suitable to building spaces and structure.

\subsection{Local community acceptances for building new use}

Community acceptance is one conditions of success and sustainability of re-use project and public participatory in choosing the new use of heritage building ensures the conservation process and interaction between building and its environment [9].

\section{Proposed building according to guidelines}

Heritage buildings in holy Makkah can be divided into two main items according to heritage conservation policy; (Zone A) heritage buildings in central area and (Zone B) outside central area.

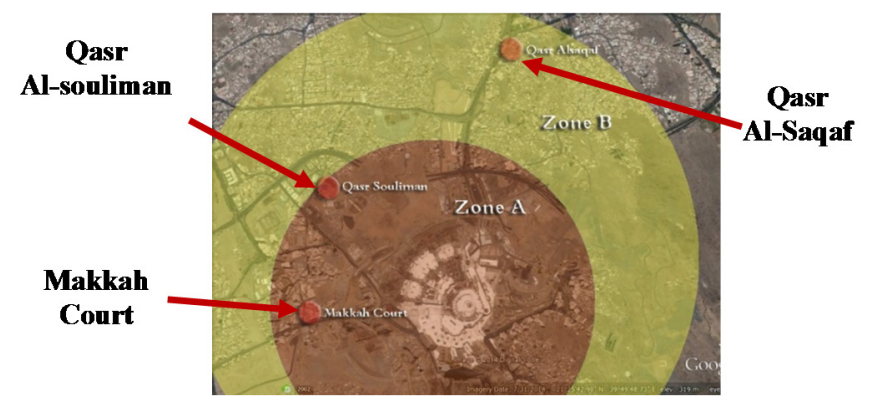

Figure 6: Selected heritage buildings in zone A and zone B.

\subsection{Heritage buildings in central area (zone $\mathrm{A}$ )}

Although the central area is very sensitive area and Holy Mosque is the only constant in this area, but there are two very important buildings in this area (Qasr Al-souliman - Makkah court) so we have to conserve these building according to the previous principal and the new use of the building must serve the Holy Mosque.

Qasr Al-souliman [10]: Qasr Al-souliman is located in Garwl district and it is $2 \mathrm{~km}$ from the Holy Mosque, it was owned by Al-sheikh Hamd Al-souliman state minster in the early Saudi kingdom. Building importance comes from its distinguished architectural character which reflects Al-Hijaz architecture and the building owned by important political person, Fig. 7 . 

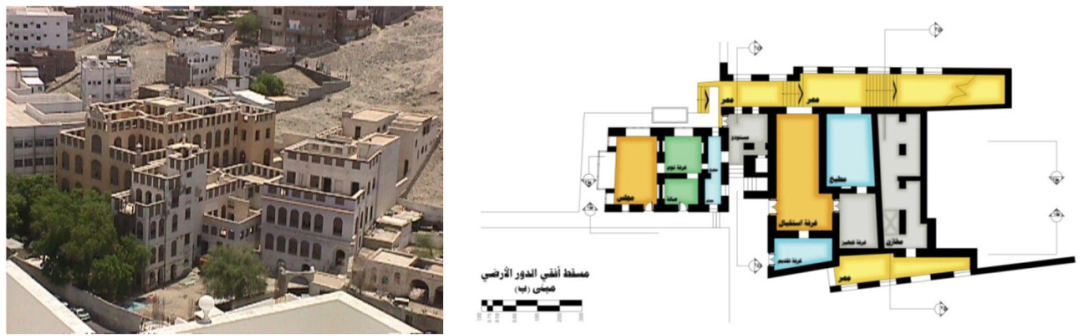

Figure 7: Qasr Al-souliman architectural character.

Makkah Court: Makkah court architectural character reflects another kind of character which affected Makkah architectural character which proves that the area is affected by different characters, Fig. 8.
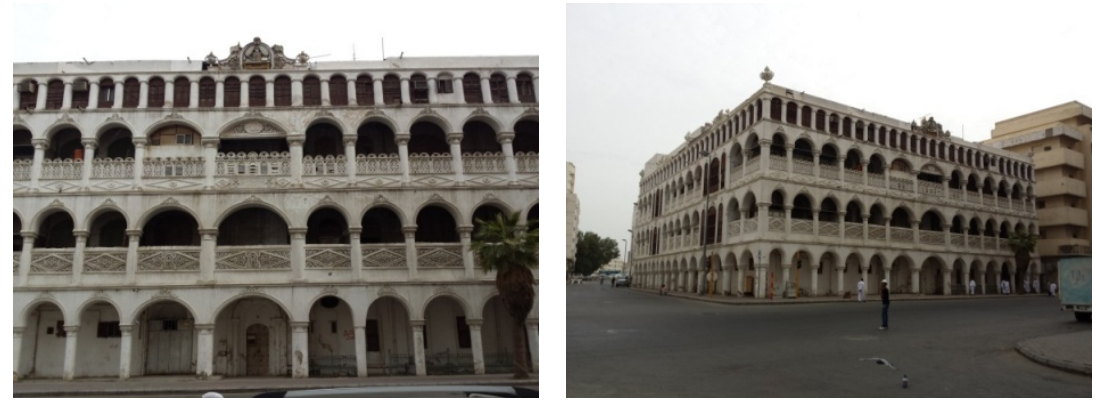

Figure 8: Makkah Court architectural character.

\subsection{Heritage buildings out of central area (zone B)}

This area has more chances than another area because we can be free to deal with conservation and building re-use in it. This area has one of the most distinguished building in Makkah (Qasr Al-Saqaf) its importance is related to his architectural character and it attended very important historical event because it attended $\mathrm{Al}$ Hijaz people's allegiance to king Abdulaziz, Fig. 9.
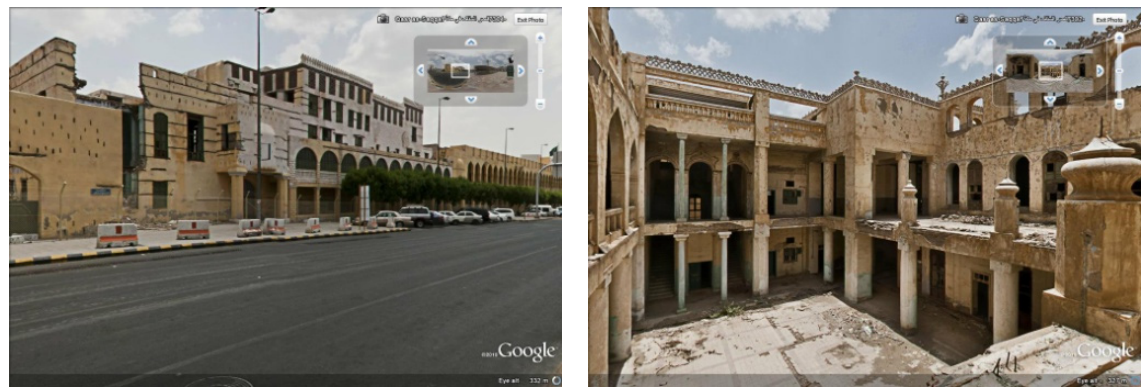

Figure 9: Qasr Al-Saqaf architectural character. 


\section{Results and recommendations}

Results and recommendations can be summarized in the following points:

\subsection{Results}

- Conservation approach for each zone should respect the characteristics of this zone (place identity) to achieve the required balance between the processes of urban development and conservation.

- Conservation processes are not limited only to direct contact with buildings/areas of value, but go beyond it to take advantage of heritage vocabulary and distinctive characteristics of these buildings/areas in various methodologies and techniques in order to raise awareness of heritage and community memory.

- Re-use of the heritage buildings in the central zone can contribute positively to the protection of the heritage value of these buildings provided that these processes take place in the framework of respect for the constants of this zone.

- Community acceptance is a milestone in the social participatory process which will ensure the success and sustainability of conservation and re-use processes.

\subsection{Recommendations}

- It's important to accelerate the process of defining criteria for determination of different action zones and defining the roles and conditions of each zone for conservation and re-use processes.

- Raising the community awareness of the heritage values of this essential area empowers the community participation which represents the required protection cover for conservation and re-use processes.

- Rapid urban development processes require to deal quickly with heritage buildings in the central area through conservation and re-use plan in respect to the constants of this area.

- It's important to formulate a specialized multi-disciplines committee with participation of the community representatives to set the roles of selecting the suitable new uses of the heritage buildings with the urban development plans to enhance and support conservation processes.

\section{Acknowledgement}

The authors would like to thank the deanship of scientific research at Umm AlQura University (Project\# 43408003) for the financial support.

\section{References}

[1] Al salafi, gameel \& Albes, Abdul Hamid, Saudi Arabia experience in rooting architectural heritage and conserving it in holy Makkah, The High 
Commission for the Development of Riyadh, Riyadh, Saudi Arabia, (1424 H./2003 CE).

[2] SBAI, Ahmad, Makkah Studies in Politics and Science, Sociology and Architecture, the Secretariat to celebrate the centenary of the founding of the Kingdom of Saudi Arabia, (1419 H./1998 CE).

[3] Fekry, Mohammed \& Sawi, Mohamed Samir, The Road to Makkah between the Problems and Hope towards the Future Vision for the Axes of the Movement's to the Holy Mosque, Urban in Makkah: the reality and the future, the fourteenth annual meeting of the Saudi committee for urban, Makkah, (2007).

[4] Al Ahmadi, yousef, Proposals for the Development of the Central Area in Makkah, neighborhoods and the road network, an article published, Al Madinah Newspaper, Issue 16660, (1429 H./2008 CE), p. 18.19.

[5] Bayoumi, Ali, Urban Development and Heritage Conservation - Case Study Rashid city, thesis of master degree, Alexandria university, (1985), p. 4.

[6] Cantell, Sophie, The Adaptive Reuse of Historic Industrial Buildings: Regulation Barriers, Best Practices and Case Studies, thesis of master degree, Virginia Polytechnic Institute and State University, USA, 2005.

[7] Ross, Michael, Planning and Heritage Policy and Procedures, second edition, published in the Taylor \& Francis e-Library, 2005.

[8] Elbelkasy, Mohamed, Interactive Relation between the Reuse of the Heritage Buildings and their Environment: a Comparative Study between (Qusier and Fewa), thesis of master degree, Mansoura University, Egypt, 2006.

[9] R.K. Maikhuri, S. Nautiyal, K.S. Rao, K.G. Saxena, Conservation Policy People Conflicts: a Case Study from Nanda Devi Biosphere Reserve (a World Heritage Site), India, Elsevier Science B.V, 2001.

[10] Al salafi Jamil, Others, Summer Training Presentation - Qasr Al-Souliman, department of Islamic architecture, Umm Al-Qura university, 2010. 